\title{
Use of non-invasive neuromodulation in the treatment of pain in temporomandibular dysfunction: preliminary study
}

\author{
Uso da neuromodulação não invasiva no tratamento da dor em disfunção temporomandibular: \\ um estudo preliminar
}

Tatyanne dos Santos Falcão Silva1, Melyssa Kellyane Cavalcanti Galdino¹, Suellen Mary Marinho dos Santos Andrade', Luciana Barbosa Sousa de Lucena ${ }^{1}$, Renata Emanuela Lyra de Brito Aranha ${ }^{1}$, Evelyn Thais de Almeida Rodrigues ${ }^{1}$

\section{ABSTRACT}

BACKGROUND AND OBJECTIVES: In temporomandibular disorder, the pain is a very present and striking symptom, with a tendency to chronicity, through mechanisms of maladaptive neuroplasticity. In the face of this, transcranial direct current stimulation appears as a possible strategy for the treatment of chronic pain in the temporomandibular disorder. This study aimed to evaluate the efficacy of anodal transcranial direct current stimulation in the pain symptoms and anxiety levels in individuals with chronic myofascial temporomandibular disorder. METHODS: The participants received three different types of intervention in a randomized order: anodic in the primary motor cortex, in the dorsolateral prefrontal cortex and sham stimulation.

RESULTS: There were significant improvements in clinical pain in all stimulation protocols, with a relief of approximately $40 \%$ $(p=0.001)$. There was no significant difference in the effect of the transcranial direct current stimulation between the different types of stimulation $(\mathrm{p}=0.14)$. There was a positive impact on anxiety symptoms, leading to a significant decrease in state anxiety levels $(\mathrm{p}=0.035)$ and trait $(\mathrm{p}=0.009)$.

CONCLUSION: The use of the transcranial direct current stimulation improved the health status of patients with chronic myofascial temporomandibular disorder, promoting pain relief, decreased level of anxiety, and quality of life.

Keywords: Orofacial pain, Rehabilitation, Transcranial stimulation by continuous current.

Tatyanne dos Santos Falcâo Silva - Dhttps://orcid.org/0000-0002-0744-3504; Melyssa Kellyane Cavalcanti Galdino - Ohttps://orcid.org/0000-0001-7180-3458; Suellen Mary Marinho dos Santos Andrade - Dhttps://orcid.org/0000-0002-6801-0462; Luciana Barbosa Sousa de Lucena - (Dhttps://orcid.org/0000-0002-2097-0544; Renata Emanuela Lyra de Brito Aranha - (Dhttps://orcid.org/0000-0003-0352-4689; Evelyn Thais de Almeida Rodrigues - (Dhttps://orcid.org/0000-0003-2169-9052.

1. Universidade Federal da Paraíba, Joăo Pessoa, PB, Brasil.

Submitted on September 30, 2018

Accepted for publication on March 11, 2019.

Conflict of interests: none - Sponsoring sources: none.

Correspondence to:

Cidade Universitária, s/n - Castelo Branco III

58051-085 João Pessoa, PB, Brasil.

E-mail: tatyannefalcao@yahoo.com.br

(c) Sociedade Brasileira para o Estudo da Dor

\section{RESUMO}

JUSTIFICATIVA E OBJETIVOS: $\mathrm{Na}$ disfunção temporomandibular, a dor aparece de forma frequente e marcante, com tendência à cronicidade, através de mecanismos de neuroplasticidade mal adaptativo. Diante disso, a estimulação transcraniana por corrente contínua surge como uma possível estratégia de tratamento da dor crônica em disfunção temporomandibular. O presente estudo objetivou avaliar a eficácia da estimulação transcraniana por corrente contínua anódica nos sintomas dolorosos e, por conseguinte, nos níveis de ansiedade em indivíduos com disfunção temporomandibular muscular crônica.

MÉTODOS: Os participantes receberam três tipos diferentes de intervenção cuja ordem foi randomizada: anódica no córtex motor primário, na região cortical dorsolateral pré-frontal e estimulação simulada.

RESULTADOS: Houve melhorias significativas para a dor clínica em todos os protocolos de estimulaçáo, com um alívio de aproximadamente $40 \%(\mathrm{p}=0,001)$. Não houve diferença significativa no efeito da estimulação transcraniana por corrente contínua entre os diferentes tipos de estimulação $(\mathrm{p}=0,14)$. Ocorreu impacto positivo sobre os sintomas de ansiedade, com diminuiçấo significativa nos níveis de ansiedade estado $(\mathrm{p}=0,035)$ e traço $(\mathrm{p}=0,009)$.

CONCLUSÁO: $\mathrm{O}$ uso da estimulação transcraniana por corrente contínua melhorou a condiçáo de saúde dos portadores de disfunção temporomandibular muscular crônica, promovendo um alívio do quadro álgico, diminuição do nível de ansiedade, além de gerar qualidade de vida.

Descritores: Dor orofacial, Estimulação transcraniana por corrente contínua, Reabilitação.

\section{INTRODUCTION}

Temporomandibular dysfunction (TMD) is a disease of high prevalence that affects the masticatory muscles and/or the temporomandibular joint. Among the symptoms, pain appears frequently and markedly, with a tendency to chronicity ${ }^{1.2}$. Chronic pain represents a significant public health problem that impacts the performance of daily activities, physical and psychosocial functioning, as well as the patients' quality of life $(\mathrm{QoL})$, generating a high cost for society and the health system ${ }^{1,3-5}$. Studies indicate that chronic pain results from a constant stimulus in the central nervous system (CNS), which in turn leads to central 
sensitization where there are changes in the excitability of the neuronal membrane due to physiological and structural changes. This mechanism is characterized by maladaptive neuroplasticity but can be reversed with treatment ${ }^{6-8}$.

Chronic TMD pain is a complex and multidimensional phenomenon that is often associated with an altered emotional state $^{9-16}$, requiring a multidisciplinary treatment that involves different therapies. Some aim to treat the muscles, others act on dental occlusion or joint structures, and there are those whose main focus is the psychoemotional factor ${ }^{1,17-19}$.

It is believed that this neuronal modification, coupled with the emotional imbalance present in many patients with this disorder, leads to an unsatisfactory response to traditional therapies such as patient education in relation to self-care, pharmacotherapy, acupuncture, stabilizing occlusal splint, biofeedback, ultrasound, transcutaneous electrical nerve stimulation (TENS), cognitive-behavioral therapy, among others ${ }^{1,6,9,12,17,18}$.

Given this context, it is evident the need for a therapy that acts directly on the CNS. This can be accomplished with drugs. However, many patients are refractory or have adverse effects, as the dependence and/or tolerance ${ }^{1,17,18}$. Given that, it is important to have new treatments involving the neuromodulation and neuroplasticity mechanisms, as the transcranial direct-current stimulation (tDCS), that can be a therapeutical alternative and also to complement the different types of treatment already in use ${ }^{20-23}$. Moreover, the tDCS corroborates the need to give to preference the reversible and non-invasive procedures ${ }^{1,17,18}$.

tDCS emerges as a possible TMD treatment modality, to modify the pattern of the cortical activity and restore the normal activation of pain processing centers, and consequently, promoting pain relief ${ }^{22,23}$. It is a simple, low-cost, non-invasive, painless, safe and well-tolerated technique ${ }^{20,23-27}$.

Some studies show that the use of tDCS protocols is promising, with good results in reducing pain symptoms in patients with chronic pain ${ }^{20,23,24,26,28-31}$. The analgesic effect has been reported with anodic stimulation, mainly in the primary motor cortex (M1) 26-28,30,32-37. However, there is another protocol option of anodic stimulation that corresponds to the dorsolateral region of the prefrontal cortex (DLPF), which demonstrates the involvement in the processing of the emotional component of pain ${ }^{13,24,35,38-40}$. However, these results are still scarce and inconclusive, which indicates the need for further investigation, especially when it comes to $\mathrm{TMD}^{21,31,32,39,41,42}$.

In this context, it is pertinent to investigate alternative methods in the treatment of chronic muscular TMD in order to increase the range of possibilities and, therefore, to promote pain relief, functional recovery and, consequently, better QoL for a greater number of patients $s^{1,3,10,22}$. Considering the lack of studies comparing the effect tDCS in patients with chronic muscular TMD, the objective of the present study was to evaluate and compare the efficacy of anodic tDCS applied in different cortical regions (M1 and DLPF) to treat the painful symptoms and, therefore, the levels of anxiety in patients with TMD with chronic pain.

\section{METHODS}

A preliminary double-blind, cross-sectional, controlled study was conducted with three intervention arms, which sequence was determined at random.

Initially, the sample consisted of patients with chronic muscular TMD who sought treatment at the Orofacial Pain Control Service of the University Hospital Lauro Wanderly (HULW) of the Federal University of Paraíba (UFPB). Due to the difficulty in finding participants for the study, we used printed and electronic ads, direct contact or health professional referrals from for the recruitment of volunteers. After the volunteers contact, screening appointments were scheduled for the evaluation of the selection criteria.

Participants were evaluated by a trained researcher (P1), using the Diagnostic Criteria for Research in Temporomandibular Dysfunction (RDC/TMD) to confirm the TMD diagnosis. Those who met the eligibility criteria were invited to participate in the study. Those who agreed signed the Free and Informed Consent Term (FICT), in two copies, after a thorough reading and explanation of all the research procedures.

To be included in the study, the individual should: (1) have previously signed the FICT; (2) be in the age range of 18-60 years, regardless of gender; (3) have a diagnosis of muscular TMD corresponding to group I of RDC/TMD Axis I); (4) have a pain score equivalent to 4 or higher on the visual analog scale (VAS), present regularly for 6 months or more; (5) the presence of moderate depressive symptoms assessed by Axis II of the SCL-90 scale (RDC/TMD); (6) not being pregnant; (7) have no metal or electronic devices implanted in the head; (8) have no history of alcohol or drug abuse in the past 6 months; (9) not taking carbamazepine in the last 6 months (use of modulating CNS activity drugs); (10) have no history of epilepsy, stroke, moderate to severe traumatic brain injury, or migraine; (11) did not perform neurosurgery; (12) not having psychiatric disorder, such as schizophrenia or bipolar disorder; (13) have no other source of pain similar to muscular TMD, such as fibromyalgia.

The present study had the following exclusion criteria: (1) two absences during the treatment sessions; (2) miss any inclusion criteria during the study, as becoming pregnant in the case of women.

To characterize the sample, a sociodemographic questionnaire was used to collect information on age, gender, religion, marital status, schooling, family income, history of illness, use of drugs, treatments performed or in progress.

In order to evaluate the levels of anxiety, pain and overall perception of change, the following instruments were used: The State-Trait Anxiety Inventory (STAI), VAS, and the Perception of Change Global Scale (PCGS).

- The STAI objectively assesses both aspects of anxiety: trait and condition. It is an instrument with 40 descriptive statements about the person's feelings, distributed in two parts (trait and state of anxiety), where each part is formed by 20 statements and the answers are given in a Likert-type scale of four points (1 - absolutely not to 4 - very much). The score of each questionnaire 
ranges from 20 to 80 , with an anxiety level rating of low (20 to 33 ), average (33 to 49) and high (49 to 80$)^{43}$.

- PCGS is an understandable instrument capable of measuring the perception of change in health status and satisfaction with the treatment of patients with chronic musculoskeletal pain. It is a one-dimensional measure in which individuals classify their improvement associated with intervention on a 7-item scale ranging from 1 (no change) to 7 (much better $)^{44}$.

- The VAS allows the subjective experience of pain to be converted into numerical data. Subjects were asked to mark their score on the horizontal rating scale from zero to 10 representing the pain intensity, in which zero means the absence of pain, (1-3) mild pain, (4-7) moderate pain, and (8-10) intense pain. It is a widely used instrument with valid and reproducible results for pain measurement ${ }^{45}$.

Participants were allocated in a single group and received three different types of intervention, and the order was randomized for each participant. The treatment protocols were: 1. Anodic tDCS on the left M1 cortex (C3) and cathodic in the right supraorbital region (Fp2), 2. anode on the left DLPF (F3) and cathode on the right supraorbital region (Fp2), and 3. simulated tDCS (placebo) with the same electrode arrangement as the first protocol (C3 and Fp2), but the current was stopped after 30 seconds, following the protocol of previous studies ${ }^{21,22,39,42}$.

The neurostimulator used was the TCT (Research Version) developed by Trans Cranial Research Limited (Hong Kong, China), with a kit containing the neurostimulator pads, sponges, rubber, electrodes, and connecting cables. The positioning of the electrodes followed the 10/20 international electroencephalogram system. They were wrapped by $5 \times 7 \mathrm{~cm}$ of sponge moistened with saline solution at $0.9 \%$.

The procedure took place in three steps, each step with five sessions. Each session lasted 20 minutes and was held daily (from Monday to Friday). A $2 \mathrm{~mA}$ current with a current density equivalent to $0.05 \mathrm{~A} / \mathrm{m} 2$ was applied. The stimulation protocol used (regarding intensity, frequency of sessions, electrode/ position size, and duration of treatment) was based on previous studies $^{21-23,39,42}$.

The painful symptoms and level of anxiety were quantified prior to initiation of treatment. Then, the order of the three types of intervention that each participant received was randomized, and the interventions started. At the end of the five sessions of each type of intervention, reevaluations were made regarding the levels of pain and anxiety, as well as the application of scales regarding the global perception of change and level of confidence. Based on previous studies, there was a four-week wash-out period between the different types of stimulation to avoid undesirable residual effects (carry-over) ${ }^{21.46-48}$. Thus, participants were re-evaluated for pain and anxiety levels before and after each step of the five stimulation sessions, with a fourweek wash-out interval between the different treatment protocols. During the study, no participant received any other type of treatment for the disease in question, avoiding any effect besides the neuromodulation (except for the sporadic use of analgesic in the wash-out period).
The randomization was done by online computer software (www.random.org). The team involved in the study was properly trained and blinded. For this purpose, each researcher was responsible for one step, without access to the other information. Regarding the role of each researcher $(\mathrm{P})$, we had diagnosis (P1), randomization and hidden allocation (P2), treatment (P3), data collection (P1) and data analysis (P1).

In order to blind the allocation, we used opaque and sealed envelopes, sequentially numbered. The participants were identified by codes and were not aware of the type of intervention they received in the study.

The clinical trial was registered at clinicaltrials.gov (registration number NCT03285685) after the approval of the HULW Ethics Committee in Research of the University (CAAE Opinion number 64862817.0.0000.5183).

\section{Statistical analysis}

The numerical data were presented in mean and standard deviation, and their distribution was evaluated by the Kolmogorov-Smirnov normality test. The alpha value was set at $5 \%$ $(\mathrm{p}<0.05)$. The analysis was performed with the SPSS statistical package version 21.0.

The data were analyzed by repeated-measures ANOVA, followed by the Bonferroni's post-hoc test. The primary dependent variable was pain intensity, and the factors were the different stimulation sites (M1, DLPF, and placebo) and time (at baseline, after five stimulation sessions and four weeks later). The secondary dependent variable, the trait-state of anxiety level, was analyzed similarly, with the scores presented in terms of mean and standard deviation.

The adverse effects were investigated after each stimulation session, and the data analysis was also performed by repeated measures ANOVA. The results of the Global Perception of Change and Confidence Level scales were presented by mean and standard deviation, which were analyzed by one-way ANOVA. The presence of correlations between the studied variables was investigated using the Pearson correlation coefficient.

\section{RESULTS}

The present study went from March 2017 to December 2017. A total of 151 patients were screened, 13 met the eligibility criteria, but only nine accepted to participate in the study. After signing the FICT, the sequence of the different types of stimulation was randomized. During the study, four individuals were excluded from the research.

With regard to the loss of follow-up, one participant received only the first tDCS step and was excluded since he no longer had pain. Others three participants gave up the last step due to lack of time. Therefore, only five participants concluded the study (Figure 1).

Table 1 shows the main variables that characterized the sample, such as gender, age, duration of pain, VAS and STAI T and E data. The sample comprised only women, possibly because the studies show that female has two to three times more the risk of developing $\mathrm{TMD}^{48,50,51}$. 


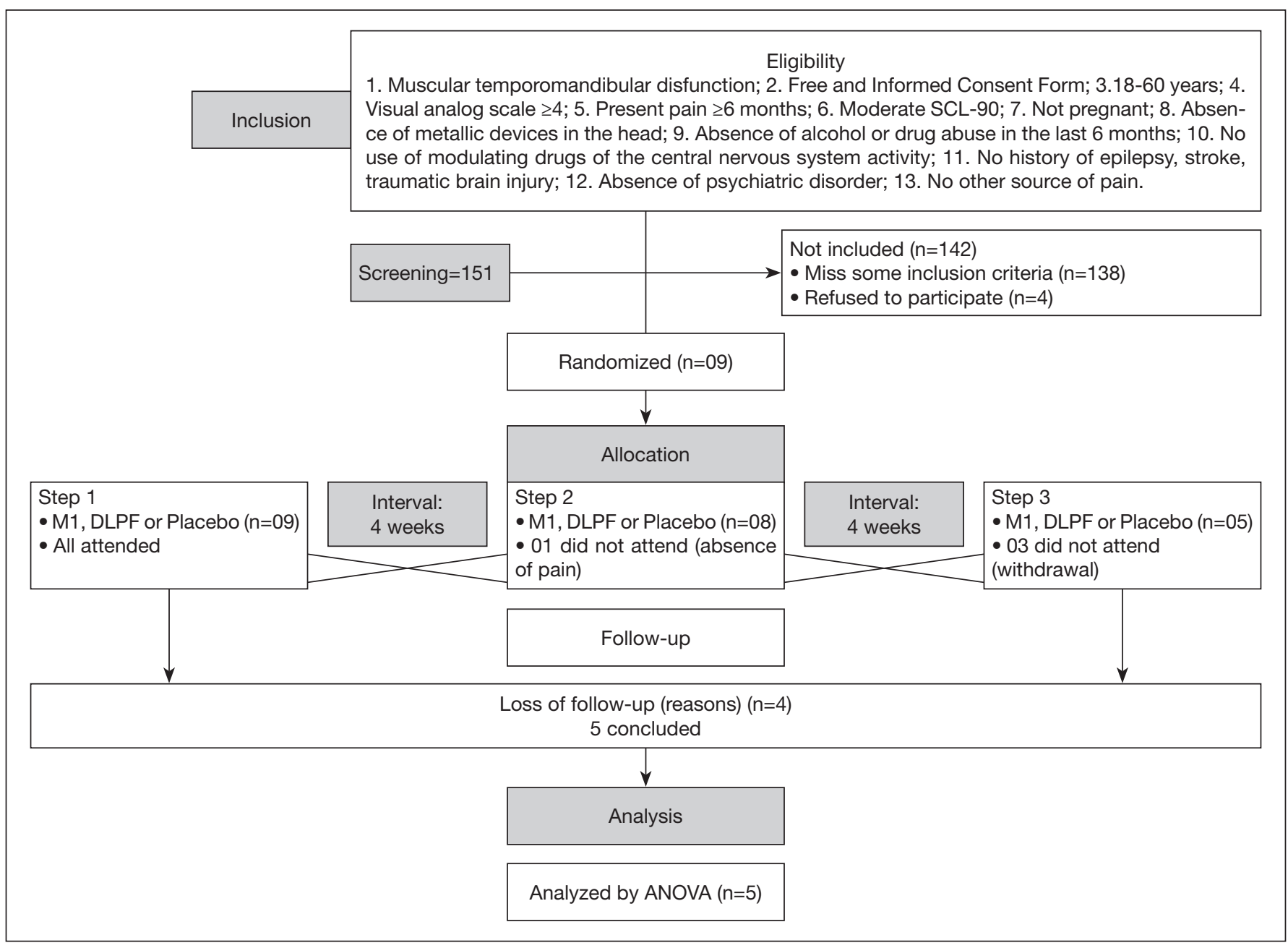

Figure 1. CONSORT flowchart with the sequence of the study development $\mathrm{DLPF}=$ dorsolateral region of the prefrontal cortex.

Table 1. Characterization of the sample with clinical and demographic data

\begin{tabular}{lccc}
\hline Characterization of the sample $(\mathrm{n}=5)$ & Mean (SD) & Minimum & Maximum \\
\hline Age (years) & $31(10)$ & 22 & 48 \\
Duration of pain (months) & $16(12)$ & 08 & 36 \\
VAS & $6.8(0.8)$ & 36 & 50 \\
STAI-E & $44.8(6)$ & 33 & 55 \\
STAI-T & $47.2(9.7)$ & 04 & 15 \\
\hline
\end{tabular}

$\mathrm{SD}=$ standard deviation; $\mathrm{n}=$ number of participants; $\mathrm{BDI}=$ Beck's depression inventory; VAS = visual analog scale; STAl= State-Trait Anxiety Inventory.

All participants had used some type of analgesic and/or muscle relaxant drug before the study. Sporadically, the use of analgesics (paracetamol or dipyrone) was reported in the wash-out period not to influence the results of the study. None were taking central-acting drugs during study participation or had any comorbidities.

According to the VAS scores pre and post-treatment, both the active stimulation and placebo generated significant improvement ( $p=0.001$ and CI:0.93-3.47) with a decrease equivalent to $37 \%$ in the intensity of pain. In the tDCS in M1, it was observed an average difference pre and post-treatment of $2.8(40 \%)(\mathrm{p}=0.012$ and CI:0.6-5) in the pain score. It was smaller in the DLPF region, only one score of improvement ( $\mathrm{p}=0.69$ and $\mathrm{CI}:-1.2-3.2)$. However, there was no significant difference in the tDCS effect between the types of intervention ( $\mathrm{p}=0.14)$ (Table 2$)$.

Table 2 shows a substantial improvement in pain, especially in M1 and placebo stimulation ( $\mathrm{p}=0.012$ and CI:0.6-5). However, after four weeks of placebo stimulation, there was a large decrease in analgesia, including worsening in three of the five participants $(\mathrm{p}=0.003$ e CI: $-6,29--1.3)$.

Table 2. tDCS effect on pain intensity pre, post-intervention and after 4 weeks

\begin{tabular}{lccccc}
\hline $\begin{array}{l}\text { tDCS } \\
\text { type }\end{array}$ & $\begin{array}{c}\text { VAS pre, } \\
\text { mean } \\
(\mathrm{SD})\end{array}$ & $\begin{array}{c}\text { VAS post, } \\
\text { mean (SD) }\end{array}$ & p-value & $\begin{array}{c}\text { VAS } \\
\text { post-4w, } \\
\text { mean (SD) }\end{array}$ & p-value \\
\hline M1 & $7(1)$ & $4.2(2.6)$ & 0.14 & $4.4(1.6)$ & 0.28 \\
DLPF & $4.4(2.6)$ & $3.4(1.8)$ & & $2.6(1.6)$ & \\
Placebo & $4.8(1.7)$ & $2(1)$ & & $5.8(2.7)$ & \\
Total & $5.4(2)$ & $3.2(2)$ & $0.001^{*}$ & $4.2(2.3)$ & 0.15 \\
\hline
\end{tabular}

$\mathrm{p}=$ value represents the significance by the repeated measures ANOVA test; tDCS = transcranial direct-current stimulation; DLPF $=$ dorsolateral region of the prefrontal cortex; VAS $=$ visual analog scale ${ }^{*} \mathrm{p}<0.05$. 
Figure 2 shows that after four weeks the pain relief remained in the active stimulation protocols (M1 and DLPF), with an improvement in pain in the DLPF region, equivalent to $41 \%$. However, according to the repeated measures ANOVA test, there was no difference between the different stimulation protocols $(\mathrm{p}=0.28)$.

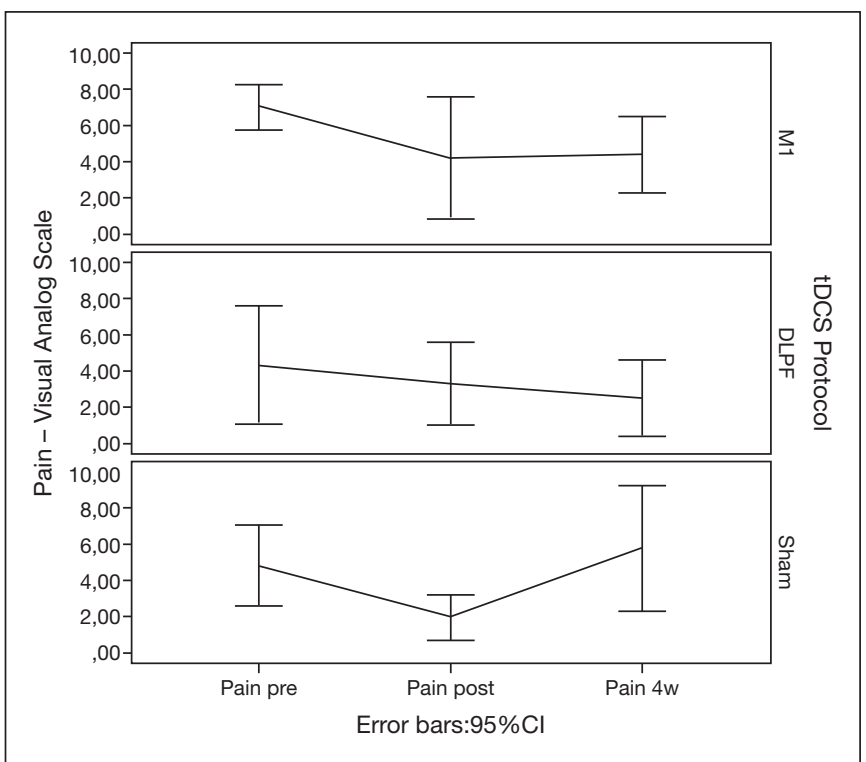

Figure 2. Visual analog scale scores per stimulation protocol according to time (pre, post-intervention, and after 4 weeks)

tDCS = transcranial direct-current stimulation; DLPF = dorsolateral region of the prefrontal cortex.

tDCS had a positive impact on the anxiety symptoms traced by STAI (Table 3). There was a significant decrease in levels of anxiety state $(\mathrm{p}=0.035)$ and trait $(\mathrm{p}=0.009)$ after the stimulation sessions. However, there was no difference between the types of intervention in both the anxiety state $(p=0.43)$ and trait $(p=0.69)$. Moreover, Pearson's correlation coefficient did not detect a linear relationship between the pain and anxiety variables (state: $\mathrm{r}=0.46$ and $\mathrm{p}=0.081$; trait: $\mathrm{r}=0.47$ and $\mathrm{p}=0.86$ ) (Table 3).

Table 3. Mean effect of tDCS on the level of state and trait anxiety after the intervention

\begin{tabular}{lccc}
\hline Variables & Mean (SD) & Cl95\% & -value \\
\hline STAI-E & $4.8(7.3)$ & $0.39-9.2$ & 0.035 \\
STAI-T & $4.1(5.2)$ & $1.2-7$ & 0.009 \\
\hline
\end{tabular}

$p=$ value represents the significance by the repeated measures ANOVA test; $\mathrm{Cl}=$ confidence interval; tDCS $=$ transcranial direct-current stimulation; STAI = State-Trait Anxiety Inventory.

Participants showed a high level of confidence in the treatment received, on a scale ranging from 1 to 5 . It is noteworthy that when participants received the placebo stimulation, they reported a slightly higher confidence (Mean [SD]: 4.4 [0.8] and CI: 3.5-5.5) compared to M1 regions (Mean [SD] : 4 [0.7] and CI: 3-4.8) and DLPF (Mean [SD]: 4.2 [0.8] and CI: 3-5.2), with no significant difference $(p=0.74)$. There was a negative correlation between the confidence level and intensity of pain after the treatment $(r=-0.61$ and $\mathrm{p}=0.015)$, as well as a positive correlation between confidence and global perception of change $(\mathrm{r}=0.612$ and $\mathrm{p}=0.015)$.

Through the PCGS, the participants demonstrated a moderate and significant change in their health state, performance of daily activities, emotions and QoL due to the improvement in the pain situation, with an average score of approximately $5(\mathrm{SD}=1.3$ and $\mathrm{CI}: 4.1-5.7)$, in a scale from zero to 7. This change has a slightly higher value in the tDCS in the cortical M1 area (Mean [SD]: 5.4 [1.1] and CI: 4-6.8), but there was no difference between the different stimulation protocols $(\mathrm{p}=0.67)$.

Concerning the adverse effects during tDCS sessions, all three types of stimulation were well tolerated. When present, they had low intensity with no difference between the different stimulation protocols $(p>0.05)$. After each stimulation session, the participants answered a questionnaire that listed some adverse effects, rating them on a 1 to 4 scale in absent, mild, moderate, or severe. No skin lesions were observed under or near the areas where the electrodes were positioned. No participant reported severe discomfort or worsening of the clinical picture during the intervention. Thus, it was confirmed that tDCS is safe and well tolerated, with tingling, itching and burning among the most prevalent adverse symptoms $s^{39,52,53}$.

Since it was a blind study, when questioned after treatment, all subjects who participated in the study believed that they had received the active current.

\section{DISCUSSION}

The present study observed as primary endpoint a significant improvement in all stimulation protocols. Especially with the M1 and placebo stimulation, soon after the stimulation, when compared to the DLPF region. After four weeks, the analgesic effect persisted mainly in the active stimulation protocols. However, there was no significant difference related to the perception of pain between the different stimulation protocols. It is worth mentioning that according to the standard recommendations of the Initiative on Methods, Measurement, and Clinical Trial Pain Evaluation (IMMPACT), the decrease in pain intensity by $50 \%$ is considered to be of substantial importance, and a $30 \%$ reduction is considered a moderately satisfactory clinical improvement.

Similarly, three controlled and parallel trials investigated the use of tDCS in subjects with TMD, but the stimulation was only in the M1 cortex. Oliveira et al. ${ }^{34}$ did not find a significant difference between the groups, but they observed a great improvement in the pain intensity after the treatment, mainly in the group of active stimulation added to physiotherapy. Sakrajai et al. ${ }^{30}$ and Donnell et al. ${ }^{28}$ observed a significant difference in the pain picture in the group that received active tDCS, noting that the latter used a high definition tDCS device on M1, which allows a more focal emission of the current.

The most frequent protocol is the anodal stimulation on M1 for 20 minutes on five consecutive days, in which the pain relief lasts from two to six weeks $s^{26,28,30,36,37}$. The analgesic effect of the neurostimulation measured by VAS after four weeks of inter- 
vention showed a large decrease in analgesia due to the placebo stimulation, unlike the active tDCS in M1 and DLPF, in which the effect size tended to remain, with an improvement of 37 and $41 \%$, respectively.

As for the regions chosen in non-invasive neuromodulation for the treatment of pain, it is known that the M1, somatosensory (S1) and dorsolateral prefrontal cortices integrate what is called the "pain matrix", which can be directly reached by the tDCS, and thereby influence the dysfunctional pathway of how the pain is being processed, indirectly reaching the subcortical components ${ }^{31,32,54,55}$.

Studies have shown that the M1 stimulation, especially on the left side, produces significant clinical improvements in patients with chronic pain, which has made this cortical region the main target of several neuromodulatory techniques, including tDCS, dedicated to the improvement of chronic pain in clinical tri$\mathrm{als}^{26-28,30,32,33}$. The intricate neurophysiological mechanisms that explain the clinical efficacy of the M1 stimulation for pain relief are not fully understood. However, it is believed that its analgesic mechanisms involve the activation of top-down controls related to the excitation of the horizontal intracortical fibers and facilitating the descending control of pain inhibition. Neuroimaging studies revealed the presence of chemical pain mediation through opioidergic, glutamatergic, GABAergic and serotoner-

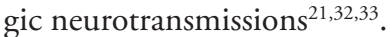

Pain due to muscular TMD is believed to be strongly related to emotional distress ${ }^{9-16,56}$. And the DLPF cortex is the fulcrum of several brain networks involved in the cognitive, affective and sensory processing, which stimulation probably mediates the analgesic effects through the modulation of affective-emotional networks related to pain ${ }^{13,38,39}$.

The left DLPF cortical region plays a role in the active control of pain perception through the bilateral modulation of the corticosubcortical and cortico-cortical pathways ${ }^{57}$. In addition, some studies have compared the effect of tDCS on M1 and DLPF cortices in individuals with chronic pain, in whom the stimulation in the DLPF region generated pain relief as good as the M1 group, and sometimes greater ${ }^{24,35,58}$.

Considering previous studies and the relationship between the left DLPF area with the emotional aspects of pain, the present study hypothesized that the anodic neuromodulation on the left side would promote a more intense analgesic effect in the stimulation protocol in the DLPF region of the cortex compared to the stimulation in the M1 cortex, since that area is shown to be responsible for the processing of the emotional component of pain, often underlining the refractoriness of treatment ${ }^{1,40}$. Although the participants reported improvement in pain when they received the anodic current in the DLPF cortex, shortly after the treatment, the analgesic effect was higher with the tDCS in M1. However, the size of the analgesic effect on both stimulation sites was similar after four weeks.

A study involving patients with fibromyalgia compared the protocol of 10 sessions, once a day, with the intensity of $2 \mathrm{~mA}$ and duration of 20 minutes. tDCS was applied to the left side of the M1 or DLPF cortex, and it was observed that both regions induced significant improvements in pain and QoL. However, the M1 group was more effective in maintaining the observed decrease in pain scores for up to 60 days $^{35}$. This same group of scholars has previously used a five-session protocol in which only the stimulation in the M1 cortex generated a significant improvement in the pain picture ${ }^{37}$. Following this reasoning, it is possible that an increase in the number of tDCS sessions, from five to ten, will provide a more pronounced analgesic effect after the stimulation in the DLPF region.

The psychosocial factor appears to be associated with TMD ${ }^{9-16}$, with patients with high levels of anxiety and/or depression being more prone to this dysfunction. And the longer the pain lasts, the higher the risks of behavioral, psychosocial, and cognitive problems, which worsens the prognosis ${ }^{14}$.

As a secondary endpoint, the levels of anxiety state-trait after the stimulation sessions were evaluated according to the STAI-E and T. Some studies support the association between pain and anxiety, especially when the pain is muscular ${ }^{14,56}$. In this study, there was a significant decrease in the anxiety state-trait levels after the therapy. However, there was no difference between the different types of intervention nor a positive correlation between pain and anxiety, possibly due to the small size of the sample. Donnell et al. ${ }^{28}$ did not find any significant difference in the anxiety state after treatment. However, Oliveira et al. ${ }^{34}$ found improvements in the depressive symptoms.

The participants reported a moderate and significant change in their health status, but there was no difference between the types of intervention $(p=0.67)$. This data corroborates previous studies that showed a relationship of negative influence between the pain and the performance of the daily activities, physical and psychosocial functioning, as well as the patients' $\mathrm{QoL}^{3-5}$.

The placebo effect corresponds to benefits attributable to brainmind responses to the context in which a treatment is administered. This effect, coupled with the fact that patients report a high level of confidence in the treatment received, justifies the high improvement of the participants who received the tDCS placebo. Similar improvement in the control group occurred in the studies by Donnell et al. ${ }^{28}$, Oliveira et al..$^{34}$, and Sakrajai et al. ${ }^{30}$. In the latter, about one-third, half the patients experienced some kind of pain relief. This phenomenon is well observed in studies involving neuromodulation in the treatment of pain ${ }^{59,60}$. Some studies have also observed a reduction of anxiety in volunteers allocated to placebo group ${ }^{61}$, an effect also observed in the present study.

On the other hand, in the placebo stimulation, the pain picture worsened markedly after four weeks when compared to active tDCS. This may be justified by the optimized effect at the molecular and clinical levels of the actual tDCS over placebo ${ }^{60,62}$, besides the fact that the clinical effects of the tDCS are cumulative and develop slowly, possibly due to neuroplastic changes ${ }^{21,23,28}$.

Based on the findings of brain imaging analysis, placebo-based analgesia is considered to be a real phenomenon, i.e., biologically measurable. They are mediated by a variety of processes including learning, expectations, and social cognition, and can influence several health-related clinical and physiological outcomes. The evidence of neuroscience believes that multiple brain systems and neurochemical mediators are involved, including opioids and dopamine $e^{61-63}$. 


\section{Limitations of the study and future outlooks}

A limitation of the present study is due to the small size of the sample since it is a preliminary study. Perhaps the sample was insufficient to detect statistically significant effects in the variables of the studied protocols. Also, there was no follow-up of brain activity before and after treatment so that no results can be given about possible neurophysiological mechanisms related to tDCS. The persistence of the tDCS analgesic effect, especially in the active stimulations after four weeks, shows that the wash-out period adopted between the study steps possibly was not enough to avoid the residual effects of the stimulation performed in the previous step, although the washout period has been defined based on previous studies ${ }^{21,46-48}$.

Another important point regarding the difficulty of the participant's compliance with the study is that his/her presence is required during 15 sessions. Also, between every five sessions, there was a four-week interval, causing the study to last approximately four months for each participant. Moreover, the lack of comparison between the efficacy of tDCS and other conventional techniques, such as the occlusal splint, is another limitation, suggesting the need for further studies about these aspects.

The results of this study should not be extrapolated to the clinical application of tDCS in the treatment of chronic TMD pain. It is suggested the development of new studies with significant sample size, aiming to quantify the effect size and differences between the types of intervention, to facilitate the decision making regarding the best choice of treatment. Given that this is a study with preliminary data, the results need to be interpreted with caution.

\section{CONCLUSION}

The present study suggests that the use of tDCS improved the health condition of patients with chronic muscular TMD, promoting relief of pain, decreased the level of anxiety, and a positive contribution to QoL. The M1 cortex was the stimulated area that showed the best result, taking into account the effect of the treatment shortly after the five sessions of neurostimulation. It is worth mentioning that the tDCS has proved to be a safe and well-tolerated instrument.

\section{REFERENCES}

1. Okeson JP. Tratamento das desordens temporomandibulares e oclusâo. Rio de Janeiro: Elsevier; 2013.

2. Sessle BJ. Acute and chronic craniofacial pain: brainstem mechanisms of nociceptive transmission and neuroplasticity, and their clinical correlates. Crit Rev Oral Biol Med. 2000;11(1):57-91.

3. Blyth FM, Van Der Windt DA, Croft PR. Chronic disabling pain: a significant public health problem. Am J Prev Med. 2015;49(1):98-101.

4. Shueb SS, Nixdorf DR, John MT, Alonso BF, Durham J. What is the impact of acute and chronic orofacial pain on quality of life? J Dent. 2015;43(10):1203-10.

5. International Association for the Study of Pain - IASP (2013) Recuperado em 16 agosto, 2016, do https://https://s3.amazonaws.com/rdcms-iasp/files/production/ public/Content/ContentFolders/GlobalYearAgainstPain2/20132014OrofacialPain/ FactSheets/Temporomandibular_Disorders_BRZ.pdf.

6. Mansour AR, Farmer MA, Baliki MN, Apkarian AV. Chronic pain: the role of learning and brain plasticity. Restor Neurol Neurosci. 2014;32(1):129-39.

7. Rodriguez-Raecke R, Niemeir A, Ihle K, Ruether W, May A. Brain gray matter decrease in chronic pain is the consequence and not the cause of pain. J Neurosci. 2004;29(44):13746-50.
8. Ji, RR, Woolf CJ. Neuronal plasticity and signal transduction in nociceptive neurons implications for the initiation and maintenance of pathological pain. Neurobiol Dis. 2001;8(1):1-10.

9. Piccin CF, Pozzebon D, Chiodelli L, Boufleus J, Pasinato F, Corrêa EC. Aspectos clínicos e psicossociais avaliados por critérios de diagnóstico para disfunçâo temporomandibular. Rev CEFAC. 2016;18(1):113-9.

10. Chisnoiu AM, Picos AM, Popa S, Chisnoiu PD, Lascu L, Picos A, et al. Factors involved in the etiology of temporomandibular disorders - a literature review. Clujul Med. 2015;88(4):473-8

11. Sipilä K, Mäki P, Laajala A, Taanila A, Joukamaa M, Veijola J. Association of depressiveness with chronic facial pain: a longitudinal study. Acta Odontol Scand. 2013;71(34):644-9.

12. Zakrzewska JM. Multi-dimensionality of chronic pain of the oral cavity and face. J Headache Pain. 2013;14:37.

13. Maeoka H, Matsuo A, Hiyamizu M, Morioka S, Ando H. Influence of transcrania direct current stimulation of the dorsolateral prefrontal cortex on pain related emotions: a study using electroencephalographic power spectrum analysis. Neurosci Lett. 2012;512(1):12-6

14. Yoon HJ, Lee SH, Hur JY, Kim HS, Seok JH, Kim HG, et al. Relationship between stress levels and treatment in patients with temporomandibular disorders. J Korean Assoc Oral Maxillofac Surg. 2012;38:326-31

15. Turk DC, Okifuji A. Psychological factors in chronic pain: evolution and revolution. Journal of Consult Clin Psychol. 2002;70(3):678-90.

16. Auerbach SM, Laskin DM, Frantsve LM, Orr T. Depression, pain, exposure to stressful life events, and long-term outcomes in temporomandibular disorder patients. J Oral Maxillofac Surg. 2001;59(6):628-34.

17. Wieckiewicz M, Boening K, Wiland P, Shiau YY, Paradowska-Stolarz A. Reported concepts for the treatment modalities and pain management of temporomandibular disorders. J Headache Pain. 2015;16:106.

18. List T, Axelsson S. Management of TMD: evidence from systematic reviews and metaanalyses. J Oral Rehabil. 2010;37(6):430-51.

19. Gremillion HA. Multidisciplinary diagnosis and management of orofacial pain. Gen Dent. 2002;50(2):178-89.

20. Fregni F, Nitsche MA, Loo CK, Brunoni AR, Marangolo P, Leite J, et al. Regulatory considerations for the clinical and research use of transcranial direct current stimulation (tDCS): review and recommendations from an expert panel. Clin Res Regul Aff. 2015;32(1):22-35

21. O'Connell NE, Wand BM, Marston L, Spencer S, Desouza LH. Non-invasive brain stimulation techniques for chronic pain. Cochrane Database Syst Rev. 2014;11(4):CD008208.

22. Fregni F, Boggio PS, Brunoni AR. Neuromodulação terapêutica: Princípios e avanços da estimulação cerebral năo invasiva em neurologia, reabilitaçáo, psiquiatria e neuropsicologia. Săo Paulo: Sarvier; 2012

23. Nitsche MA, Paulus W. Excitability changes induced in the human motor cortex by weak transcranial direct current stimulation. J Physiol. 2000;527(Pt3):633-9.

24. Choi YH, Jung SJ, Lee CH, Lee SU. Additional effects of transcranial direct-current stimulation and trigger-point injection for treatment of myofascial pain syndrome: a pilot study with randomized, single-blinded trial. J Altern Complement Med. 2014;20(9):698-704

25. Stagg CJ, Nitsche MA. Physiological basis of transcranial direct current stimulation Neuroscientist. 2011;17(1):37-53.

26. Antal A, Terney D, Kühnl S, Paulus W. Anodal transcranial direct current stimulation of the motor cortex ameliorates chronic pain and reduces short intracortical inhibition. J Pain Symptom Manage. 2010;39(5):890-903

27. George MS, Aston-Jones G. Noninvasive techniques for probing neurocircuitry and treating illness: vagus nerve stimulation (VNS), transcranial magnetic stimulation (TMS) and transcranial direct current stimulation (tDCS). Neuropsychopharmacology. 2010;35(1):301-16.

28. Donnell A, Nascimento T, Lawrence M, Gupta V, Zieba T, Truong DQ, et al. High-definition and non-invasive brain modulation of pain and motor dysfunction in chronic TMD. Brain Stimul. 2015;8(6):1085-92.

29. Jensen MP, Day MA, Miró J. Neuromodulatory treatments for chronic pain: efficacy and mechanisms. Nat Rev Neurol. 2014;10(3):167-78.

30. Sakrajai P, Janyacharoen T, Jensen MP, Sawanyawisuth K, Auvichayapat N, Tunkamnerdthai $\mathrm{O}$, et al. Pain reduction in myofascial pain syndrome by anodal transcranial direct current stimulation combined with standard treatment: a randomized controlled study. Clin J Pain. 2014;30(12):1076-83.

31. Knotkova H, Nitsche MA, Cruciani RA. Putative physiological mechanisms un derlying tDCS analgesic effects. Front Hum Neurosc. 2013;7:628.

32. Lefaucheur JP, Antal A, Ayache SS, Benninger DH, Brunelin J, Cogiamanian F, et al. Evidence-based guidelines on the therapeutic use of transcranial direct current stimulation (tDCS). Clin Neurophysiol. 2017;128(1):56-92.

33. DosSantos MF, Ferreira N, Toback RL, Carvalho AC, DaSilva AF. Potential mechanisms supporting the value of motor cortex stimulation to treat chronic pain syndromes. Front Neurosci. 2016;10:18.

34. Oliveira LB, Lopes TS, Soares C, Maluf R, Goes BT, Sá KN, Baptista AF. Transcranial direct current stimulation and exercises for treatment of chronic temporomandibular disorders: a blind randomised-controlled trial. J Oral Rehabil. 2015;42(10):723-32.

35. Valle A, Roizenblatt S, Botte S, Zaghi S, Riberto M, Tufik S, et al. Efficacy of anodal transcranial direct current stimulation (tDCS) for the treatment of fibromyalgia: 
results of a randomized, sham-controlled longitudinal clinical trial. J Pain Manag. 2009;2(3):353-61.

36. Fregni F, Freedman S, Pascual-Leone A. Recent advances in the treatment of chronic pain with non-invasive brain stimulation techniques. Lancet Neurol. 2007;6(2):188-91.

37. Fregni F, Gimenes R, Valle AC, Ferreira MJ, Rocha RR, Natalle L, et al. A randomized, sham-controlled, proof of principle study of transcranial direct current stimulation for the treatment of pain in fibromyalgia. Arthritis Rheum. 2006;54(12):3988-98.

38. Seminowicz DA, Moayedi M. The dorsolateral prefrontal cortex in acute and chronic pain. J Pain. 2017;18(9):1027-35.

39. Cruccu G, Garcia-Larrea L, Hansson P, Keindl M, Lefaucheur JP, Paulus W, et al. EAN guidelines on central neurostimulation therapy in chronic pain conditions. Eur J Neurol. 2016;23(10):1489-99.

40. Boggio PS, Zaghi S, Fregni F. Modulation of emotions associated with images of human pain using anodal transcranial direct current stimulation (tDCS). Neuropsychologia. 2009; $47(1): 212-7$.

41. Vaseghi B, Zoghi M, Jaberzadeh S. Does anodal transcranial direct current stimulation modulate sensory perception and pain? A meta-analysis study. Clin Neurophysiol. 2014;125(9):1847-58

42. O'Connell NE, Marston L, Spencer S, DeSouza LH, Wand BM. Non-invasive brain stimulation techniques for chronic pain. Cochrane Database Syst Rev. 2018;(4):CD008208.

43. Biaggio AM, Natalício L, Spielberger CD. Desenvolvimento da forma experimental em português do Inventário de Ansiedade Traço-Estado (IDATE) de Spielberger. Arq Bras Psicol Aplicada. 1977;29(3):31-44.

44. Domingues L, Cruz E. Adaptação cultural e contributo para a validação da escala Patient Global Impression of Change. Ifisionline. 2011;2(1):31-7.

45. Bolton JE, Wilkinson RC. Responsiveness of pain scales: a comparison of three pain intensity measures in chiropractic patients. J Manipulative Physiol Ther. 1998;21(1):1-7.

46. O'Neill F, Sacco P, Nurmikko T. Evaluation of a home-based transcranial direct current stimulation (tDCS) treatment device for chronic pain: study protocol for a randomised controlled trial. Trials. 2015;16:186.

47. Amatachaya A, Auvichayapat N, Patjanasoontorn N, Suphakunpinyo C, Ngernyam, $\mathrm{N}$, Aree-Uea B, et al. Effect of anodal transcranial direct current stimulation on autism: a randomized double-blind crossover trial. Behav Neurol. 2014;2014:173073.

48. Wrigley PJ, Gustin SM, McIndoe LN, Chakiath RJ, Henderson LA, Siddall PJ. Longstanding neuropathic pain after spinal cord injury is refractory to transcranial direct current stimulation: a randomized controlled trial. Pain. 2013;154(10):2178-84

49. Bagis B, Ayaz EA, Turgut S, Durkan R, Özcan M. Gender difference in prevalence of signs and symptoms of temporomandibular joint disorders: a retrospective study on 243 consecutive patients. Int J Med Sci. 2012;9(7):539-44.

50. Schmid-Schwap M, Bristela M, Kundi M, Piehslinger E. Sex-specific differences in patients with temporomandibular disorders. J Orofac Pain. 2013;27(1):42-50.

51. Warren MP, Fried JL. Temporomandibular disorders and hormones in women. Cells Tissues Organs. 2001;169(3):187-92.

52. Brunoni AR, Amadera J, Berbel B, Volz MS, Rizzerio BG, Fregni F. A systematic review on reporting and assessment of adverse effects associated with transcranial direct current stimulation. Int J Neuropsychopharmacol. 2011;14(8):1133-45.

53. Brunoni AR, Nitsche MA, Bolognini N, Bikson M, Wagner T, Merabet L, et al. Clinical research with transcranial direct current stimulation (tDCS): challenges and future directions. Brain Stimul. 2012;5(3):175-95.

54. Legrain V, Iannetti GD, Plaghki L, Mouraux A. The pain matrix reloaded: a salience detection system for the body. Prog Neurobiol. 2011;93(1):111-24.

55. DosSantos MF, Love TM, Martikainen IK, Nascimento TD, Fregni F, Cummiford $\mathrm{C}$, et al. Immediate effects of $\mathrm{tDCS}$ on the $\mu$-opioid system of a chronic pain patient. Front Psychiatry. 2012;3:93.

56. Bertoli E, de Leeuw R. Prevalence of suicidal ideation, depression, and anxiety in chronic temporomandibular disorder patients. J Oral Facial Pain Headache. 2016;30(4):296-301

57. Brighina F, De Tommaso M, Giglia F, Scalia S, Cosentino G, Puma A, et al. Modulation of pain perception by transcranial magnetic stimulation of left prefrontal cortex. J Headache Pain. 2011;12(2):185-91.

58. Andrade SM, de Brito Aranha REL, de Oliveira EA, de Mendonça CTPL, Martins WKN, Alves NT, et al. Transcranial direct current stimulation over the primary motor vs prefrontal cortex in refractory chronic migraine: a pilot randomized controlled trial. J Neurol Sci. 2017;378:225-32.

59. Antal A, Paulus W, Rohde V. New results on brain stimulation in chronic pain. Neurol Int Open. 2017;1:E312-5.

60. Greene CS, Goddard G, Macaluso GM, Mauro G. Topical review: placebo responses and therapeutic responses. How are they related? J Orofac Pain. 2009;23(2):92-107.

61. Holmes RD, Tiwari AK, Kennedy JL. Mechanisms of the placebo effect in pain and psychiatric disorders. Pharmacogenomics J. 2016;16(6):491-500.

62. DosSantos MF, Martikainen IK, Nascimento TD, Love TM, DeBoer MD, Schambra HM, et al. Building up analgesia in humans via the endogenous $\mu$-opioid system by combining placebo and active tDCS: a preliminary report. PLoS One. 2014;9(7):e102350

63. Wager TD. Atlas LY. The neuroscience of placebo effects: connecting context, learning and health. Nat Rev Neurosci. 2015;16(7):403-18 